\section{Surviving disaster: what comes after the trauma? ${ }^{\dagger}$}

\author{
JONATHAN R. T. DAVIDSON
}

Foa (1993), with post-traumatic depression receiving particular attention. Attempted suicide is a significant risk (Davidson et al, 1991), and Hull et al describe substantial guilt, a feature which we have found to be predictive of a poor response to amitriptyline (Davidson et al, 1993). Additional post-traumatic difficulties include excessive alcohol intake. Hull et al also observe a high rate $(44 \%)$ of 'caseness' elicited by the General Health Questionnaire (GHQ; Goldberg \& Hillier, 1979), again underscoring the fact that full PTSD by no means accounts for the entire spectrum of post-traumatic psychological problems. Partial PTSD is often found in the community, with a prevalence rate of $4.1 \%$ (Davidson et al, 2002). We therefore need to be alert to a broad spectrum of psychiatric problems after major trauma.

\section{EARLY IDENTIFICATION OF THOSE AT RISK FOR PTSD}

Exposure to a single, discrete and clearly identifiable traumatic event affords the opportunity for early detection. What could help us here? Although no predictive test gives high diagnostic accuracy for PTSD, there are some useful clinical leads. Hull et al found that serious physical injury (fractures), persistent anger and witnessing the death or injury of others were all associated with more severe PTSD symptoms at follow-up. Others have found that elevated heart rate within the first week following trauma (Shalev et al, 1998) and low urinary cortisol (Resnick et al, 1995) increase the risk of developing chronic PTSD. Additional warning signals include severe depression and dissociation. Extent of trauma exposure and lack of social support are also important considerations (Brewin et al, 2000). Intensity of exposure to (combat) trauma can influence treatment response as far into the future as
20-40 years (Davidson et al, 1993), which suggests that the most severely traumatised group of survivors may be in particular need of vigorous early treatment. Could such treatment alter the trajectory of the disorder? By paying attention to these phenomena, we may be better able to detect and treat post-traumatic stress at an earlier stage.

\section{PREVENTION OF PTSD}

Prevention can be primary (preventing exposure to trauma), secondary (preventing development of PTSD immediately after exposure to trauma) and tertiary (prevention of worsening once PTSD has emerged).

Two studies have suggested promising biological approaches in secondary prevention: medication using propranolol for 2 weeks after accident trauma (Pitman et al, 2002); and medication with hydrocortisone for 12 days in septic shock (Schnelling et al, 2001). Interestingly, each of these treatments targets core central nervous system (CNS) disturbances which are found in PTSD. Beta-adrenergic receptor blockade counteracts the massive sympathetic response seen after trauma. It also lowers the heart rate, and thereby may abolish a symptom which predicts (or maybe leads to) PTSD and which is a symptom of established PTSD. Hydrocortisone, which may compensate for low cortisol status, was successful in preventing the development of PTSD in the Schnelling et al study. We do not yet know whether secondary prevention can be effectively accomplished by psychological interventions. Studies by Deahl et al (2000), Larsson et al (2000) and Gidron et al (2001) suggested possible benefit, but standard single-session debriefing (Conlon \& Fahy, 2001) is not to be recommended.

Data for prevention of PTSD by treating acute stress disorder are limited but encouraging, both for drug therapy with imipramine in children (Robert et al, 1999) and for cognitive-behavioural therapy in adults (Bryant et al, 1999).

\section{TREATMENT OF ESTABLISHED PTSD AND RELATED DISORDERS}

An unusual, but welcome, finding from Hull et al's study is the high rate of treatment utilisation, suggesting relative 
ease of access to treatment services, greater community support and less personal resistance to accepting help. We must not ignore the finding that non-professional support was perceived as being by far the most helpful. The low levels of perceived benefit from medication $(28 \%)$ and group therapy $(14 \%)$ are matters of concern. These more expensive procedures need to be used in the most cost-effective way. Clearly we need to work harder to optimise treatment benefit, and to be cognisant of what our patients think about the treatments in which we are invested. As far as medication is concerned, the study does not report which agents were used, their doses, duration of administration, or whether side-effects were a problem; all these matters need to be addressed because response rates to medications can be good. Recent studies of selective serotonin reuptake inhibitors (SSRIs) and mirtazapine, for example, indicate rates of response above $50 \%$. Cognitive therapy is also highly effective for PTSD, yet it can be associated with a troublesome rate of attrition (Scott \& Stradling, 1997).

In thinking about treatment response, we need to define our goals. For many with PTSD full remission is attainable (Connor et al, 1999; Hembree \& Foa, 2000) and is an expectation which we can set for ourselves and our patients. Although the Piper Alpha follow-up study points to a decline over time in the rates of PTSD, we cannot automatically assume that those without the diagnosis are necessarily well; as the authors state, we need to be attentive to intermediate levels of pathology. It appears that those who survived well the collapse of Piper Alpha had good premorbid functioning and support networks. Lack of neuroticism has been found to predict response to a tricyclic drug in chronic PTSD (Davidson et al, 1993).

Comprehensive treatment of PTSD and related disorders can be approached along a continuum of early detection, decision-making about the appropriateness of treatment in the acute phase, selection of such a treatment, decision-making as to whether and when early treatment can be discontinued, and then follow-up. For some individuals long-term treatment will be needed, although others will manage adequately without. Yet others will recover, but relapse later. Nonprofessional support can pick up an important part of the recovery burden. When people are physically injured, as

JONATHAN R. T. DAVIDSON, MD, Duke University Medical Center, Department of Psychiatry and Behavioral Sciences, Trent Drive, Yellow Zone, 4th Floor, Room 4082 B, Box 3812, Durham, NC 277I0, USA. Tel: 919684 2880; fax: 919684 8866; e-mail: jonathan.davidson@duke.edu

(First received 5 June 2002, accepted 5 June 2002)

indicated by Alexander's group, effective liaison needs to be established between professionals involved in the delivery of psychiatric, medical and surgical care. Such a model of care may have especial applicability after a disaster wherein rapid intervention is more feasible and there is the possibility of early detection, secondary or tertiary prevention, and follow-up.

\section{CONCLUSION}

Last, but not least, the authors report the subjects' own views of how they were affected by the tragedy. Detrimental effects on the quality of relationships and leisure activities, on well-being and on employment were all noted, serving as a reminder to the clinician that the disorder is more than its defining symptoms. A counterbalancing observation, however, was the fact that $61 \%$ perceived some good resulting from their painful experience, whether this was enriched relationships, emotional growth or financial security, reminding us that out of trauma can come further resilience. How much this was the result of self-directed effort and how much a result of treatment is a question worth asking. It may well be that a crucial task of treatment is to help strengthen the resilience of trauma survivors, enabling them to cope more effectively with stressful events and with the general demands of life, as we have previously shown can be achieved (Connor et al, 1999). Resilience has been a neglected topic of study in the therapeutics of PTSD, perhaps related to the lack of suitable measures. As there may be a characteristic neurobiology associated with resilience (Morgan et al, 2000), the subject deserves further study.

No study can answer all the questions, and the authors acknowledge some very reasonable limitations of their follow-up study. Nevertheless, it is a valuable, carefully conducted survey, which gives us the opportunity to consider a number of major questions concerning outcome after exposure to serious trauma.

\section{DECLAR ATION OF INTEREST}

None.

\section{REFERENCES}

Brewin, C. R., Andrews, B. \& Valentine, J. D. (2000) Meta-analysis for risk factors for posttraumatic stress disorder in trauma-exposed adults. Journal of Consulting Clinical Psychology, 68, 748-766.

Bryant, R. A., Sackville, T., Dang, S. T., et al (1999) Treating acute stress disorder: an evaluation of cognitive behavioral therapy and supportive counseling techniques. American Journal of Psychiatry, I56, 1780-1786.

Conlon, L. \& Fahy, T. J. (200I) Psychological debriefing for acute trauma - a welcome demise? Irish Journal of Psychological Medicine, 18, 43-44.

Connor, K. M., Sutherland, S. M., Tupler, L. A., et al (1999) Fluoxetine in post-traumatic stress disorder. Randomised, double-blind study. British Journal of Psychiatry, 175, 17-22.

Davidson, J. R. T. \& Foa, E. B. (1993) Posttraumatic Stress Disorder: DSM-IV and Beyond (eds J. R. T. Davidson \& E. B. Foa), pp. 229-235. Washington, DC: American Psychiatric Press.

—, Hughes, D. C., Blazer, D. G., et al (199I) Posttraumatic stress disorder: an epidemiological study. Psychological Medicine, 2I, 713-72I.

_ , Kudler, H. S., Saunders, W. B., et al (1993) Predicting response to amitriptyline in posttraumatic stress disorder. American Journal of Psychiatry, $\mathbf{I 5 0}$ 1024-1029.

—, Tharwani, H. M. \& Connor, K. M. (2002)

Davidson Trauma Scale (DTS): normative scores in the general population and effect sizes in placebo-controlled SSRI trials. Depression and Anxiety, 15, 75-78.

Deahl, M., Srinivasan, M., Jones, N., et al (2000)

Preventing psychological trauma in soldiers: the role of operational stress training and psychological debriefing. British Journal of Medical Psychology, 73, 77-85.

Gidron, Y., Gal, R., Freedman, S., et al (200I)

Translating research findings to PTSD prevention: results of a randomized-controlled pilot study. Journal of Traumatic Stress, 14, 773-780.

Goldberg, D. P. \& Hillier, V. F. (1979) A scaled version of the General Health Questionnaire. Psychological Medicine, 9, 139-145.

Hembree, E. A. \& Foa, E. B. (2000) Posttraumatic stress disorder: psychological factors and psychosocial interventions. Journal of Clinical Psychiatry, 6I (suppl. 7), S33-S39.

Hull, A. M., Alexander, D. A. \& Klein, S. (2002) Survivors of the Piper Alpha oil platform disaster: 
long-term follow-up study. British Journal of Psychiatry, I8I, 433-438.

\section{Larsson, G., Michel, P-O, \& Lundin, T. (2000)}

Systematic assessment of mental health following various types of posttrauma support. Military Psychology, 12, 121-135.

Morgan III, C. A., Wang, S., Southwick, S. M., et al (2000) Plasma neuropeptide-Y concentrations in humans exposed to military survival training. Biological Psychiatry, 47, 902-909.

Pitman, R. K., Sanders, K. M., Zusman, R. M., et a (2002) Pilot study of secondary prevention of posttraumatic stress disorder with propranolol. Biological Psychiatry, 5I, 189-192.

Resnick, H. S., Yehuda, R., Pitman, R. K., et al (1995) Effect of previous trauma on acute plasma cortisol level following rape. American Journal of Psychiatry, 152 , 1675-1677.

Robert, R., Blakeney, P., Villareal, C., et al (1999) Imipramine treatment in pediatric burn patients with symptoms of acute stress disorder: a pilot study. Journal of American Academy of Child and Adolescent Psychiatry, 38, 873-882.
Schnelling, G., Briegel, J., Roozendaal, B., et al (200I) The effect of stress doses of hydrocortisone during septic shock on posttraumatic stress disorder in survivors. Biological Psychiatry, 50, 978-985.

Scott, M. J. \& Stradling, S. G. (1997) Client compliance with exposure treatments for posttraumatic stress disorder. Journal of Traumatic Stress, 10, 523-526.

Shalev, A. Y., Sahar, T., Freedman, S., et al (1998) A prospective study of heart rate response following trauma and the subsequent development of posttraumatic stress disorder. Archives of General Psychiatry, 55, 553-559. 